\title{
Erratum to: Time-Optimal Interception of a Moving Target by a Dubins Car
}

\author{
M. E. Buzikov ${ }^{1 *}$ and A. A. Galyaev ${ }^{1 * *}$ \\ ${ }^{1}$ Trapeznikov Institute of Control Sciences, Russian Academy of Sciences, Moscow, 117997 Russia \\ e-mail: *me.buzikov@physics.msu.ru, ${ }^{* *}$ galaev@ipu.rssi.ru \\ Received August 3, 2021; revised August 3, 2021; accepted August 3, 2021
}

DOI: $10.1134 /$ S0005117921070122

The article "Time-Optimal Interception of a Moving Target by a Dubins Car," written by M. E. Buzikov and A. A. Galyaev, was originally published electronically in Springer-Link on 1 June 2021 without Open Access. After publication in volume 82, issue 5, pages 745-758 the authors decided to make the article an Open Access publication. Therefore, the copyright of the article has been changed to (C) The Author(s), 2021 and the article is forthwith distributed under the terms of a Creative Commons Attribution 4.0 International License (http://creativecommons.org/licenses/by/4.0/, CC BY), which permits use, duplication, adaptation, distribution and reproduction of a work in any medium or format, as long as you cite the original author(s) and publication source, provide a link to the Creative Commons license, and indicate if changes were made.

The original article can be found online at https://doi.org/10.1134/S0005117921050015 